\title{
A comparative study of visual field defects seen in patients with low-tension glaucoma and chronic simple glaucoma
}

\author{
R. A. HITCHINGS and S. A. ANDERTON \\ From the Glaucoma Unit, Moorfields Eye Hospital, High Holborn, London WCIV 7AN
}

SUMMARY In a study comparing the visual field defects of patients with chronic simple and low-tension glaucoma differences in the nature of the defect were found between the 2 groups. Patients with low-tension glaucoma had far 'steeper sided' defects than those seen in chronic simple glaucoma $(\mathrm{p}<0 \cdot 01)$.

\begin{abstract}
The concept of a 'soft' or low-tension glaucoma has been known for over 120 years. ${ }^{1}$ However, a controversy still exists concerning the exact nature of this condition. Ideas on pathogenesis range from lowtension glaucoma being a variety of chronic openangle glaucoma with the laminar cribrosa 'giving way' at normal intraocular tension ${ }^{2}$ to the idea that lowtension glaucoma is a variety of anterior ischaemic neuropathy. ${ }^{3}$ Comparison of the visual field defects seen in low-tension and open-angle glaucoma might be expected to show differences between the 2 conditions. However, even the type of the visual field defect seen in patients with low-tension glaucoma has provoked considerable discussion. In a recent critical review combined with examination of 32 of his own cases Levene ${ }^{4}$ concluded that a far higher proportion $(92 \%)$ of patients with low-tension glaucoma had visual field defects to within $5^{\circ}$ of fixation compared with $20 \%$ of 160 consecutive cases of chronic openangle glaucoma. However, Motolko and coworkers ${ }^{5}$ could find no difference in the nature of the visual field defect when comparing 160 eyes with low-tension glaucoma with 154 eyes having chronic open-angle glaucoma matched according to cup-disc $(C / D)$ ratio.

It seemed worthwhile to carry out a prospective study of the visual field defects seen in these 2 conditions.
\end{abstract}

\section{Material and methods}

This study compares the nature of the visual field defect seen in patients with low-tension glaucoma matched with patients having chronic open-angle Correspondence to $\mathrm{Mr}$ R. A. Hitchings. glaucoma. Each patient with low-tension glaucoma fulfilled the following criteria: $(a)$ 'glaucomatous cupping'; $(b)$ nerve fibre bundle type of visual field defect; (c) intraocular pressures below $21 \mathrm{mmHg}$ both at presentation and at the time of 24-hour phasing when off all treatment: $(d)$ open angles.

These patients all had progressive low-tension glaucoma. ${ }^{6}$ The eyes included in this study were matched on a one-to-one basis with eyes from patients who suffered from chronic simple glaucoma. The matched pairs had to be patients whose ages differed by no more than 10 years. The matched pairs of eyes had to have the following common characteristics: (1) intraocular pressure $<21 \mathrm{mmHg}$ at the time of test; (2) the same type of nerve fibre bundle visual field defect; (3) 6 out of 8 points on the 1-4 isoptre had to be within $5^{\circ}$ of each other (Fig. 1 shows the radii chosen, which on crossing the 14 isoptre identified the 8 points).

Both groups of patients chosen for this study were long-term attenders at the glaucoma unit. Each patient had undergone multiple visual field examinations beforehand.

For the purposes of this study each patient underwent a standard 3 isoptre visual field performed on the Goldmann perimeter using the Armaly/Drance technique. ${ }^{7}$ On the same day but after a suitable rest static profile perimetry was performed on the Goldmann perimeter with the same background illumination ( $31.5 \mathrm{asb})$ along the following meridans: $45^{\circ}, 135^{\circ}, 225^{\circ}$, and $315^{\circ}$. The technique used has been reported elsewhere. ${ }^{8}$ All tests were performed by the same technician (S.A.A.). on the same machine. 


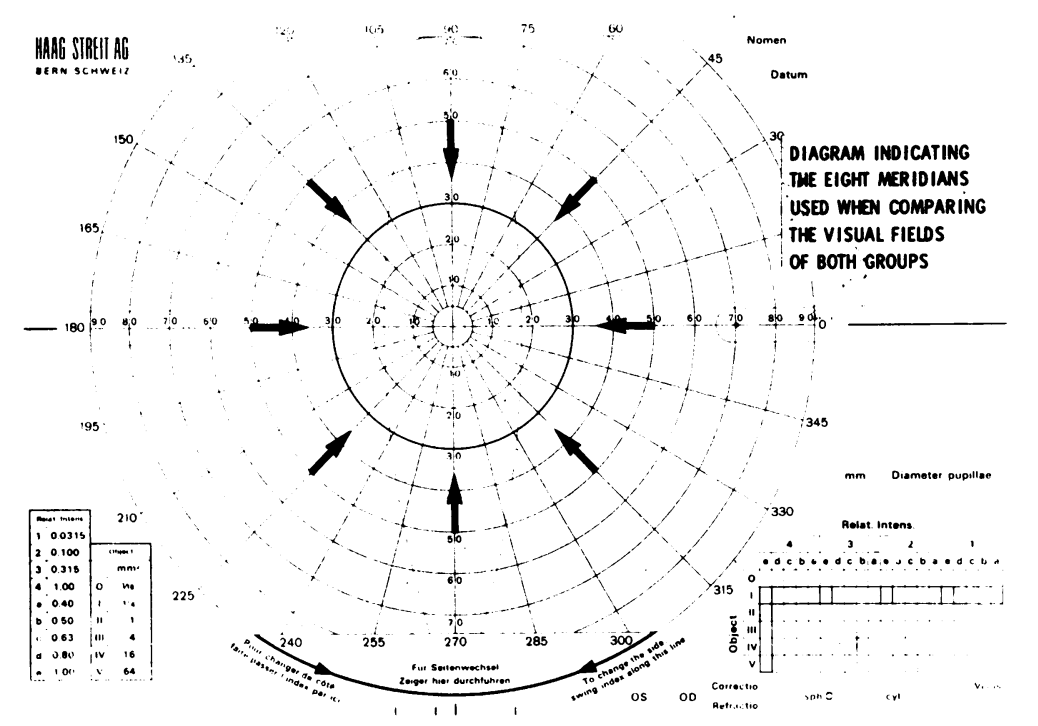

Fig. 1 Diagram indicating the 8 radii used when comparing the visual fields.

The 'steepness' of the slope of the visual field defect was compared in those eyes that had a normal hemifield on profile perimetry. For this study the 'steepness' was measured as the number of degrees along the particular radius from the start of the defect (top of the slope) until the defect became absolute (the bottom of the slope). The top of the slope was identified by comparing the perimetry profile of the affected radius with the diametrically opposite profile in the normal hemifield (i.e., $45^{\circ}$ and $225^{\circ}, 135^{\circ}$ and $315^{\circ}$ ). A perimetry profile was considered 'normal' if no depression exceeding $0.5 \mathrm{log}$ unit intensity occurred. In comparisons of the 2 opposite profiles the start of a slope was identified when, at the same distance from fixation, the sensitivity on one side was $>0.5 \log$ unit less than that on the other side.

The figures for steepness on the 2 meridians measured for each eye were averaged. The averaged figures were used to compare the steepness of the slope of the visual field defect in the 2 groups.

\section{Results}

Thirty eyes from 23 patients with low-tension glaucoma were matched against 30 eyes of 26 patients with chronic open-angle glaucoma. The mean acuity difference for matched pairs on the Snellen's test type was 0.8 of a line. Intraocular pressures were $<21$ $\mathrm{mmHg}$ on or off medicines. Pupil size was $<2 \mathrm{~mm}$ in 25 of the 30 pairs.

Five types of visual field defect were identified by the Armaly/Drance technique. These were: an isolated scotoma of $10^{\circ}$ or more in area, a nasal step, an arcuate scotoma, a combination of the nasal step and arcuate scotoma, and an altitudinal defect. The prevelance of these 5 types of visual field defect were noted (Fig. 2). The numbers recorded refer to the defects in hemifields and therefore do not correspond with the number of eyes tested, for some eyes had a defect in both upper and lower half of the visual field.

The distance from fixation along 4 meridia $\left(45^{\circ}\right.$, $135^{\circ}, 225^{\circ}$, and $315^{\circ}$ ) of a defect on the $1-4$ isoptre was found for each of these 60 eyes (Fig. 3). Although more of the eyes with low-tension glaucoma than

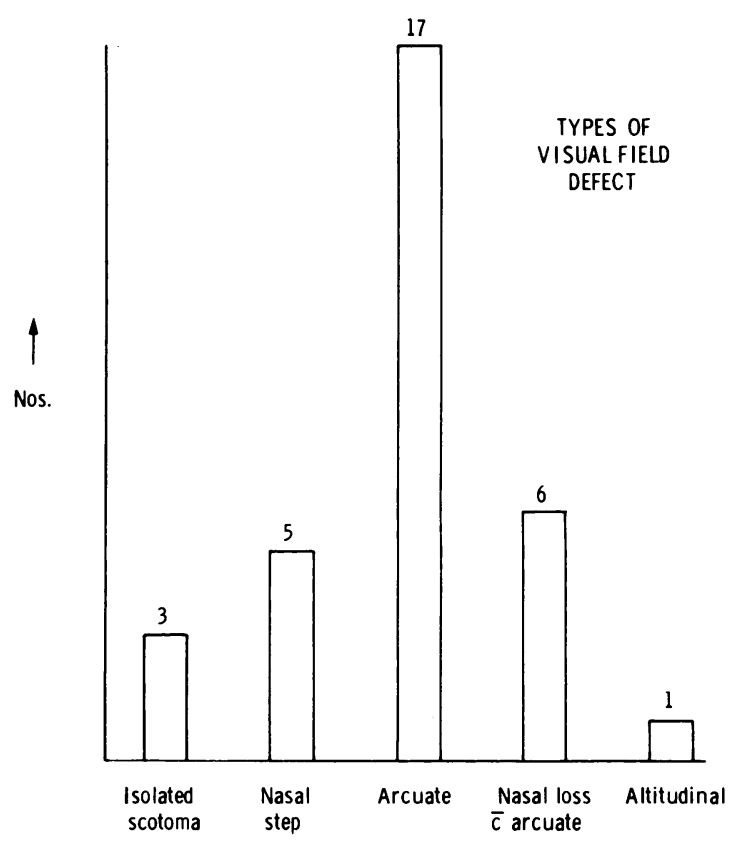

Fig. 2 Types of visual field defect. 


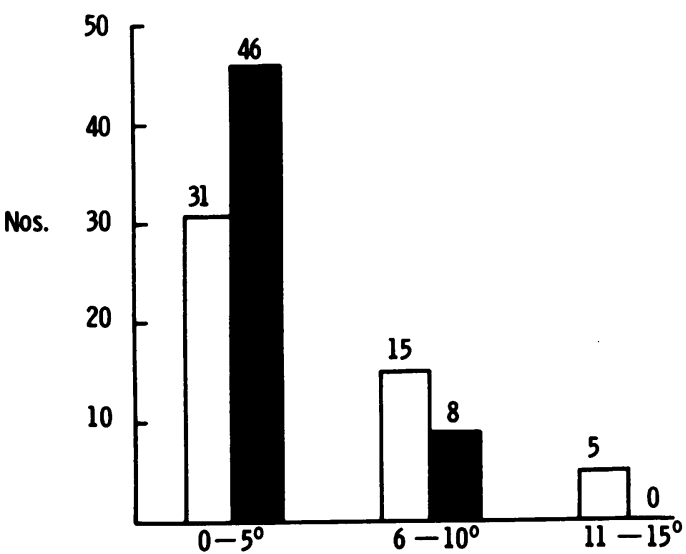

Distance absolute defect from fixation (degrees )

Fig. 3 Comparison of LTG and CSG fields: relationship of the absolute scotoma profile to fixation. $L T G=$ low-tension glaucoma, $\square$. CSG=chronic simple glaucoma $\square$.

eyes with chronic simple glaucoma had defects within $5^{\circ}$ of fixation, there was considerable overlap between the 2 groups.

Twenty-five of the $\mathbf{3 0}$ matched pairs had a normal upper and lower 'hemi' field when tested by the Armaly/Drance technique. However, on static profile only 15 matched pairs with a normal hemifield were identified. The other 10 matched pairs had significant relative defects $\left(>10^{\circ}\right.$ in width and $>0.50$ log unit sensitivity) or absolute defects in either one or both eyes of the pair.
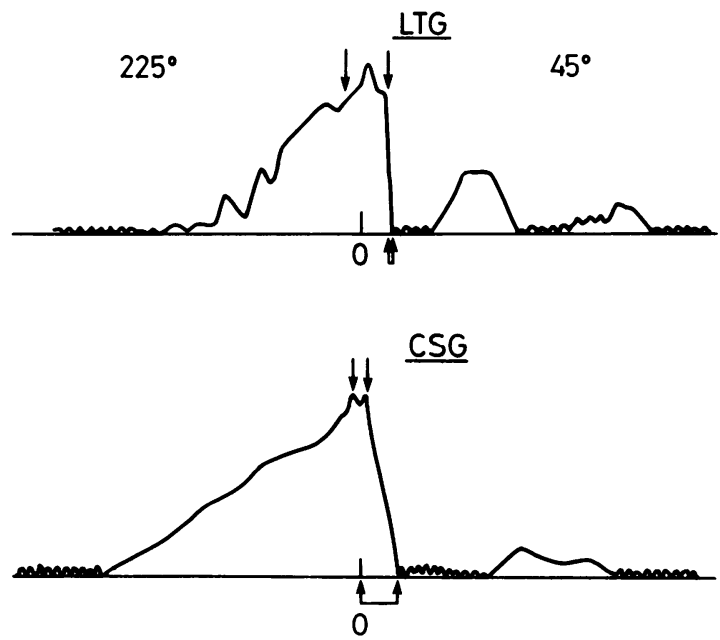

Fig. 4
An analysis of the 15 matched pairs with normal hemifields on static profile perimetry was carried out to compare the 'steepness' of the walls of the defect in the 2 groups.

$$
\begin{aligned}
& \mathrm{n}=15 \\
& \bar{y}=-2 \cdot 8667 \\
& \mathrm{SD}=3 \cdot 5328
\end{aligned}
$$

Testing mean for difference from zero (2-tailed test)

$$
\begin{aligned}
& t=3 \cdot 143 \\
& \mathrm{DF}=14 \\
& \mathrm{p}=0 \cdot 007 .
\end{aligned}
$$

For the 15 pairs used in this study a highly significant difference existed between the steepness of the slope in low-tension glaucoma and chronic simple glaucoma, the former group having the steeper sided slope (Figs. 4 and 5).

\section{Discussion}

This paper has shown that in comparisons of the visual field of patients with low-tension glaucoma and chronic open-angle glaucoma a higher proportion of the former group had an absolute visual field defect to within $5^{\circ}$ of fixation, though the difference between the 2 groups was not absolute. A highly significant difference existed between the 2 groups on comparison of the 'steepness' of the slope of the visual field defect. We were impressed by the uniform
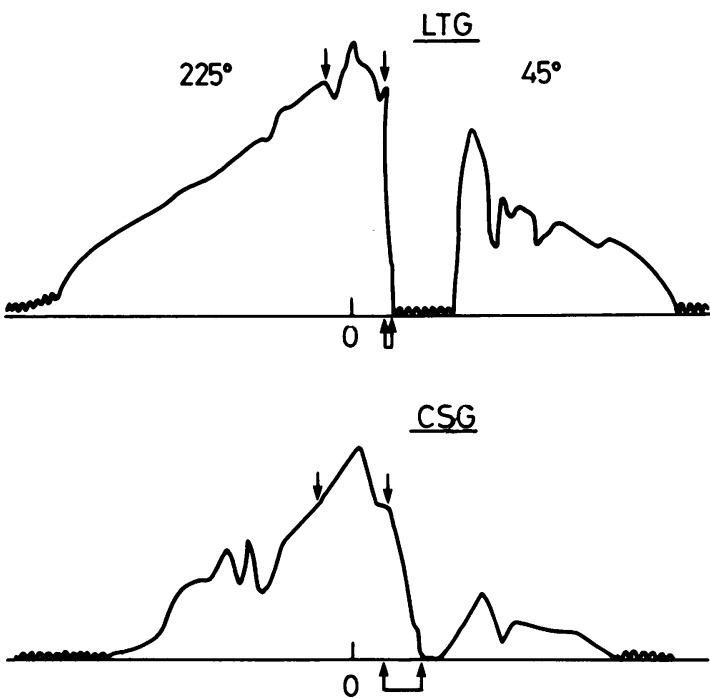

Fig. 5

Figs. 4 and 5 Comparison of the visual field profiles in 2 of the 15 matched pairs tested by static profile perimetry. $L T G=$ lowtension glaucoma. CSG=chronic simple glaucoma. Separate arrows indicate start of visual field defect identified by comparison with normal hemifield. Linked arrows show distance (degrees) between start of defect (top of the slope) and absolute (bottom of the slope). 
'steepness' of the visual field defects in all our patients with low-tension glaucoma, while only a proportion of those with chronic simple glaucoma showed the same characteristic. The difference could be equated with the different changes visible on fluorescein angiography of the optic disc in patients with low-tension glaucoma and chronic simple glaucoma, all of whom had an arcuate scotoma, for while the former group showed dense filling defects on the optic disc the latter group did not always do so. ${ }^{9}$

It is interesting to try to identify reasons for the conflicting results obtained from comparison of lowtension glaucoma and chronic simple glaucoma fields. Before drawing too many conclusions from this study it should be remembered that the sample studied here was small, and it is possible that errors could arise from this fact. However, what could be the reason for similarities between the visual fields in the 2 groups noted on earlier studies?

Firstly, a single or few isoptres used to identify a visual field defect could give a misleading impression of 'closeness' of the defect to fixation. Secondly, and perhaps of greater importance in this discussion is the use of similar $\mathrm{C} / \mathrm{D}$ ratios to identify patient pairs. We have noted how many of our low-tension glaucoma patients have large $C / D$ ratios, although the visual field defect may still be small in size. Chronic simple glaucoma patients with large $C / D$ ratios may often have extensive visual field defects, also close to fixation. For this reason it may be difficult to equate $\mathrm{C} / \mathrm{D}$ ratio with the stage of the disease process in these 2 groups of patients, and in consequence the interpretation of results may be difficult.

The results reported here show a qualitative difference between field defects in pairs of eyes matched according to the type of field defect in patients who were, possibly, matched according to the stage of their disease. They go some way to suggest that in low-tension glaucoma a high proportion of eyes will have defects close to fixation at a comparatively early stage in the disease process, while in chronic simple glaucoma, at the same stage, this is less likely to be the case. Finally, the uniformly steep sided nature of the field defect in low-tension glaucoma suggests that the visual loss in this disease affects all visual perception within a given area of the visual field, producing 'steeply sided' (absolute) defects, while in chronic simple glaucoma this is less likely to occur.

\section{References}

1 Von Graefe A. Über die Vitrectomie bei Glaucom und über den glaucomatosen Prozess. Albrecht von Graefes Arch Klin Ophthalmol 1957; 3: 456-650.

2 Maumenee AE. The pathogenesis of visual field loss in glaucoma. In: Brockhurst RS, Boruchoff SA, Hutchinson T, Lessell S, eds. Controversies in ophthalmology. Philadelphia: Saunders, 1977.

3 Hayreh SS. Pathogenesis of optic nerve damage in visual field defect in glaucoma. In: Heilman K, Richardson WT, eds. Conceptions of a disease. Philadelphia: Saunders, 1978.

4 Levene RZ. Low tension glaucoma, a critical review and new material. Surv Ophthalmol 1980; 24: 621-64.

5 Motolko M, Drance SN, Douglas GR. Visual field defects in low-tension glaucoma. A comparison of defects in low-tension glaucoma and chronic open angle glaucoma. Arch Ophthalmol 1982; 100: 1074-7.

6 Chander PA, Grant WM. Progressive low-tension glaucoma. Glaucoma. 2nd ed. Philadelphia: Lea and Febiger, 1979.

7 Rock WJ, Drance SN, Morgan RW. A modification of the Armaly visual field screening technique for glaucoma. Br J Ophthalmol 1971; 6: 283-92.

8 Hitchings RA, Wheeler CA. The optic disc in glaucoma. IV. Optic disc evaluation in the ocular hypertensive patient. BrJOphthalmol $1980 ; 64: 232-9$.

9 Hitchings RA, Spaeth GL. Fluorescein angiography in chronic simple and low-tension glaucoma. Br J Ophthalmol 1977; 61: 126-32. 